\title{
Creating Curriculum of English for Conservative Tourism for Junior Guides to Promote Tourist Attractions in Thailand
}

\author{
Onsiri Wimontham ${ }^{1}$ \\ ${ }^{1}$ English Education Curriculum, Nakhon Ratchasima Rajabhat University, Thailand \\ Correspondence: Onsiri Wimontham, English Education Curriculum, Nakhon Ratchasima Rajabhat University, \\ Thailand. E-mail: onsiri.wimontham@yahoo.com
}

\author{
Received: January 1, 2018 Accepted: February 13, 2018 Online Published: February 15, 2018 \\ doi: 10.5539/elt.v11n3p67 URL: http://doi.org/10.5539/elt.v11n3p67
}

\begin{abstract}
This research was supported the research fund of 2017 by Office of the Higher Education Commission of Thailand. The objectives of this research are listed below.

1). To form the model of teaching and learning English for local development by English curriculum (B. Ed.) students' participation in training on out-of-classroom learning management, which focuses on the students' English skills improvement along with developing the sense of love of their home towns.

2). To create curriculum of English training for conservative tourism for junior guides in Sung Noen District, Nakhon Ratchasima Province.

3). To promote conservative tourist attractions in Sung Noen District, Nakhon Ratchasima Province among foreign tourists, and to boost the local economy so that young generations can earn income and rely on themselves in the future.

An interesting result from the research was more income gained from tourism in Sung Noen District, Nakhon Ratchasima Province between April 2016 and June in the same year. The junior guides' ability to communicate and provide information about tourism in English was evaluated. This result also accorded with the evaluation done by the youth and stakeholders on the curriculum of English for conservative tourism for junior guides, and 75 percent considered it very good, matching with the synthesis from the interview. The curriculum was created to be applicable to the local tourism context and match the need of users.
\end{abstract}

Keywords: curriculum of English for conservative tourism, junior guides, foreign tourists

\section{Introduction}

Receiving the research fund of 2016 from National Research Council of Thailand, the researcher conducted the research under the National Strategy in the theme of "The Development of People Lives' Quality from All Groups and Ages for the Sustainably Good Way of Life." The research topic is "The Study of Teenagers' problems: Case Study of Video Games addicted teenagers in Sung Noen District, Nakhon Ratchasima Province." After finishing the research as well as discussing and processing the result, the researcher found some issues about English teaching. In fact, the target group of the research was teenagers between 12-19 years of age in Sung Noen District. Out of 35 teenagers, 61 percent would like to spend their free time the most productively by participating in activities or projects of their schools, local organizations or families. After doing in-depth interview, the researcher found that the teenagers desired to improve their potential of English skills for communication in order to apply in taking examinations for higher education, and they have hoped that there would be collaboration between a university, which was Nakhon Ratchasima Rajabhat University, and the chief executive of Sung Noen Subdistrict Administrative Organization on creating activities for teenagers to support their English improvement that could create more jobs and sustainably develop quality of life in the future.

Acknowledging the information and the teenagers' requests mentioned above, the researcher managed the lesson-learned process related to the research conducted with Sung Noen Subdistrict Administrative Organization, aiming to further the research that matches the need and solve problems in this area. Officials who concerned with this research were invited such as a chief executive and officials responsible for Sung Noen youth's education and life quality enhancement. All the 14 officials took part in brainstorming session, and that led to the research topic that was "Creating Curriculum of English for Conservative Tourism for Sung Noen 
Youth Leaders." The objective was to enhance Sung Noen youth's potential in terms of English skills for communication and tourism. All participants in the meeting hypothesized similarly, that is, the research could improve English skills of the youth who participated and they could apply the acquired knowledge to their local development, especially in conservative and traditional tourism in Sung Noen District which was being popular among foreign tourists.

Before creating curriculum of English for conservative tourism for Sung Noen youth leaders, the researcher had studied conservative tourism in Sung Noen District, Nakhon Ratchasima Province. It was found that there were several conservative attractions in Sung Noen District - such as "Wat Pho Pradu," "Sim Isaan," "Khum Baan Kao," and "Khmer ancient communities" - totally 12 places. In each month, there were many foreign tourists coming to Sung Noen to appreciate the "ancient Sung Noen" ambiance. Most tourists came from ASEAN countries; however, there were tourists from Europe and North America also. The researcher received information about the growth in the number of tourists. The increase in the number of tourists led to collaboration among villages' leaders in providing services and homestay accommodation that enabled foreign tourists to stay. There were short stay, rental daily, or longer stay, rental weekly. Additional information from in-depth interview showed that 4 homestay houses had been run by the villagers such as "Baan Sook Chai," "Baan Welcome Home," "Baan Atta," and "Baan Mae Yu Yen." The villagers revealed some interesting information, that is, greater number of foreign tourists stayed in Sung Noen District between 2014-2016 because they wanted to experience conservative tourism and learn the way of life of ancient Korat people. One thing in Sung Noen District that could attract foreign tourists attention was conservation of Korat's traditional houses. Moreover, the original atmosphere of the local style was well-maintained. From interviewing, foreign tourists revealed that visiting Sung Noen District was interesting because this area was connected to Khao Yai National Park and Wang Nam Khiao, Nakhon Ratchasima.

The data collected on sites mentioned above indicated that although there were collaboration between villages' leaders and villagers on homestay business as well as setting up signs to promote conservative tourism in Sung Noen District, "a lack of tour guides giving information in English about conservative tourism in Sung Noen District" was still a problem. When moving back to the interview of Sung Noen youth leaders, the researcher found that if foreign tourists had deeply understood and appreciated way of life, tradition, and history of Sung Noen's historical attractions, they could have publicized worldwide through modern social media such as Facebook, Line, Application, and Twitter. These media could help spread information about conservative tourism in Sung Noen District quickly and be accessible by anyone who really appreciated conservative tourism. All of these could make Sung Noen District famous, and the conservative attractions could become outstanding on an international scale. More foreign tourists flooding into this area could be beneficial to tourism, accommodation business, restaurants, and local shops in Sung Noen District. As a result, Sung Noen people could have better lives and more income. They could rely on themselves in accordance with "philosophy of self-sufficient economy by King Rama IX."

Based on the need coming directly from Sung Noen people who had desired to improve tourism in Sung Noen District by using the research that could enhance youth's English potential, the research topic was "Creating Curriculum of English for Conservative Tourism for Junior Guides in Sung Noen District, Nakhon Ratchasima Province.” The key objective was to encourage the youth to participate in the training session, both in theory and in practice, based on the curriculum stated above. They were expected to be able to apply communicative English skills acquired from training to communicate with foreign tourists efficiently. The objective of this research was to ensure that the youth could be tour guides capable of introducing conservative and natural attractions, accommodation and restaurants nearby to the tourists. The researcher highly anticipated that this curriculum that had been designed could enhance not only the youth's English skills, but also the local economy, and could make more income together with the sense of love of local people's hometowns. These outcomes could inspired the youth to deepen their knowledge acquired from training on English for conservative tourism, and build on the knowledge to benefit themselves, their families and their local places in the future (Onsiri, 2016).

\section{Literature Review}

\subsection{The Use of English for Communication}

Speaking skill is significant for learning English for communication. Therefore, speakers need to apply many skills to make their listeners understand. The speakers have to express clear comprehensible feelings or ideas to the listeners. Good speakers have to know how to say appropriately on various occasions and speak fluently with the precise word choices. Speaking is one of the ways to convey feelings and ideas to the listeners and make 
them understand the speakers' purposes by using techniques leading to efficient conversation. Mentioned the meaning of English for conversation, that is, speaking is the communication of thoughts, experiences and needs of speakers with listeners. Moreover, speakers need to make the listeners understand the messages by using appropriate tone of voice, languages, and gestures according to tradition and norms in their society for proper understanding and responses (Rutcharuen. 2011).

In other words, speaking means ability to using languages including gestures, and convey clear comprehensible ideas to listeners with purpose of exchanging information between two or more people. To speak efficiently and appropriately, speakers need to choose proper words, tone of voice and non-verbal language when speaking under certain occasions, tradition or norms in their society (Parker. 2011).

The objective of teaching English for communication is to encourage learners to develop their knowledge and ability in using English for communication correctly and appropriately. Jeremy (2009) mentioned the factors of ability to speak as a tool for communication, that is, fluency and comprehensibility. Wendy (2013) said that pronunciation, vocabulary and grammar were important things that helped listeners understand messages sent based on quality of communication. All of these factors will make relevance between sentences, and to make conversation continues smoothly, learners need to have ability as follows.

\subsubsection{Grammatical Competence}

Comprehension in this aspect does not mean building ability to understand only grammar usage but also all aspects related to language - such as tone of voice, vocabulary including grammar - so that speakers can select words or phrases that are precise and suitable for communicative purposes.

\subsubsection{Sociolinguistic Competence}

Speakers can select proper forms of language based on different communicative situations, and they can use communication as a tool to develop relationship and achieve communicative purposes. They will be able to use various forms of language based on different types of speaking situations; for example, discussion, idea expression or debate.

\subsubsection{Discourse Competence}

Grammatically, if speakers know how to use connectors correctly, they can express their thoughts chronologically, and there will be consistency in their messages. All of these result in fluent and smooth conversation.

\subsubsection{Strategic Competence}

To speak efficiently, speakers need to use techniques for communication, and they can develop speakers' speaking potential effectively. Although speakers have limited knowledge of grammar, the conversation can go smoothly if the speakers can apply strategies to solving problems in communication.

In the evaluation of speaking communicative competency, Koomkhainam (2007) suggested methods as follows.

1). Repeat short sentences after teachers or recorders.

2). Read different sentences out loud.

3). Describe different objects based on learners' language level. They can describe other details related to selected objects but cannot tell what they are. The learners have to let their listeners guess what those objects are. Besides objects, the learners are required to describe people or places.

4). Describe situations by using photographs.

5). Talk about selected topics. There should be several topics so that the learners can choose what they like.

6). Perform role-play which the learners are interviewers who have to elicit information from their interviewees as much as possible and record it.

When evaluate communicative English Speaking competency, it is necessary to consider speaking competency factors in order to evaluate learners' ability in different aspects such as speaking, pronunciation, grammar, vocabulary, comprehension and fluency. Evaluation can be done in many ways; pre-evaluation, formative evaluation, and summative evaluation that is relevant to lessons already learned. Therefore, Parker (2011) presented that many experts use the factors mentioned above as criteria for evaluating competency.

\subsection{Approaches for Creating Curriculum of Communicative English Speaking}


Developing curriculum of speaking communicative English, some scholars suggested approaches and methods for teaching communicative English speaking. Jeremy (2009) mentioned 5 principles for creating curriculum of communicative English speaking as follows.

1) It is necessary to ensure that learners have will to communicate, and topics for communication should relate to them.

2). Objectives of communication should be oriented towards content rather than forms of communication.

3). Good activities should be conducted in various languages and enable learners to use different forms of language.

4). Teachers should not correct learners' mistakes immediately while learners are doing activities.

5). Teachers should not force or control learners to use only one specific form of language.

Yule (2010) suggested 5 principles for creating curriculum of communicative English speaking as follows.

1). The information transfer principle. Activities emphasizing on transferring information from one skill to another skill should be included in the curriculum.

2). The information gap principle. This principle will result in real communication situation and interaction between learners while doing activities because they need to communicate to acquire the information they want. According to this principle, communication will happen when there is information gap; thus, learners have to communicate in order to find the information they are looking for.

3). The jigsaw principle. Each learner will receive incomplete information, so they have to collect information from others. They need to communicate to exchange information and use that information to perform assigned tasks.

4). The task dependency principle. Each learner has to complete their own sub task and later combine all information together by inquiring and talking. After that, each of them has to complete major task.

5). The correction for content principle. After doing activities, learners or teachers have to check completeness and accuracy of the information exchanged between learners.

Wendy (2013) suggested principles for creating curriculum of communicative English speaking so that teachers could apply them in practice. The principles are listed as follows.

1). Learners need to be informed about objectives for learning different types of materials such as listening to news and weather forecast from radios, reading advice, giving directions, and writing letters. From this reason, learners will concentrate on activities they are engaging in order to achieve the goals.

2). Learners have to fully comprehend the language use, not partially selected parts for communication, so that they can communicate under certain circumstances efficiently.

3). The communication process is as important as forms of language. As a result, communication development should be as close to the real situation as possible.

4). Teachers should create proper activities to enable learners to learn through practice.

5). Teachers should encourage learners when they make grammatical or pronunciation mistakes and give them a chance of correcting their mistakes. This way can help learners become more confident of using language.

6). In conclusion, speaking for communication activities that are used for speaking skills improvement can give a chance to and encourage learners to practice using language in assign tasks. Thus, the role of teachers is not a dictator but an advisor who sets learning goals of each activities for learners and explains instructions clearly so that the process of exchanging information while doing activities can be done smoothly and efficiently in order.

\subsection{The Concept of Traditional and Conservative Tourism}

Anzar (2001) said that traditional and conservative tourism is one of the kinds of sustainable tourism encouraging tourists to visit man-made attractions for pleasure. They can acquire knowledge by studying local people's beliefs, understand social and traditional conditions, experience new things, and be aware of environmental and traditional conservation. This kind of tourism enables people in local communities to take part in tourism management, and aim to find the balance between tourism development and environmental protection. That is why people from all sectors need to support traditional and conservative tourism that sustainably provides the greatest benefit to all related sectors from now on. 
Thailand is a country rich in art and tradition that have been inherited form ancestors. These are priceless treasure showing how Thailand is different from others. Therefore, Thai people should understand the value and put an effort to preserve them by using knowledge and wisdom delicately so as not to let them disappear or deteriorate. In fact, some experts defined traditional tourism differently. Summarily, traditional tourism is trips that people or a group of people travel from their places they are living in to other places to appreciate the beauty and uniqueness of other ethnic groups. In addition, those people have to respect each other's culture to develop relationship, knowledge, and understanding, and to appreciate those communities' culture. It is important to produce as few negative effects on people, culture and communities' environment as possible. Meanwhile, local people who are the owners of their culture can gain benefit from tourism in terms of income and employment leading to social and economic development.

In other words, Moscardo (2003) wrote that cultural and conservative tourism is created for someone who is seeking new experience composed of learning, seeing, appreciating things - the cultural uniqueness and beauty, historical value, way of life and other ethnic groups' life style. Cultural differences - art, architecture, historic site, antique, story, historical value, way of life, language, costume, food, belief, religion, custom - are significantly attractive. They help boosting cultural tourism, and to create sustainable tourism, it is highly necessary to be responsible for fundamental cultural factors listed below.

1). Related to cultural tourism, history, historic sites, culture, and tradition need to be given precedence by conserving resources of cultural tourism as carefully as possible so that they can be passed down to younger generations.

2). Cultural tourism requires management for sustainability in terms of economy, society, and environment, and the principles of management have to produce no effect, or fewest, on the environment.

3). Cultural tourism must be managed to maintain people's way of life in terms of society and culture. It has to attract tourists who desire to study a variety of society and cultures.

4). Cultural tourism has to educate all related sectors - tourists, keepers of attractions, business owners, and local people. All sectors have to focus on learning from travelling experience and being aware of cultural tourism resource conservation.

5). Cultural tourism has to enable people in communities to participate and be advantageous to these people. Local communities have to be able to involve in tourism management and gain a benefit from tourism. This way can distribute income to people in local communities.

6). Cultural tourism has to include marketing for tourism services in accordance with principles of true conservation. Moreover, tourism business has to emphasize on cultural and environmental conservation.

7). Cultural tourism has to satisfy students in order to add more value to the experience they have gain so that they will come to visit again. Also, activities for tourists need to meet with tourists' expectation.

8). Cultural tourism has to be managed based on carrying capacity and cleanliness in the area. The number of tourists cannot exceed the maximum capacity in all aspects, and It is important to keep the tourist attractions clean all the time.

9). Cultural tourism has to be managed based on safety of tourists' lives and belongings. There has to be strict security to ensure their safety.

\subsection{Related Research}

Kwantip (2014) said that according to the document written by Bureau of Academic Affairs and Educational Standards, Office of the Basic Education Commission, the Ministry of Education about learning management towards joining ASEAN community, the role of chief local administrators and other sectors involving in joining ASEAN community was mentioned. It stated that the qualified administrators' ability to improve local education would be evaluated based on these 6 indicators: 1) vision of education management for stepping towards ASEAN community. 2) ability to manage on limited resources efficiently. 3) skills in communicative English and ICT. 4) ability to join networking and collaboration for education management for stepping towards ASEAN community. 5) ability to supervise and monitor. 6) ability to use technology as a tool to communicate within the network of ASEAN member states (Office of the Basic Education Commission, 2554). All 6 indicators show that local administration is responsible for local development and preparation for ASEAN community by seeking support from other procedures

Sumalai Nitipol conducted the research on 3 groups of target population at different ages: children, adolescents and office workers. For 20 hours, they had been trained in communicative English with various topics such as 
family tree and my hobby. The finding shows that learning potential of adolescents is better than that of others, and suitable environment has effects on learning also. Additionally, the finding indicates that media or innovation can improve learning ability of people at all ages (Larbnongsang, 2012).

Ratanakorn (2003) conducted research into promoting agricultural tourism in Prang Kum District, Chiang Rai Province. In this research, target population which was 24 adolescents attended 30-hour training session, both theoretical and practical. In practice, all 24 people in the target group were separated into groups and role-play the situation, where they had to welcome foreign tourists and take them to visit important places in Prang Kum District as well as the districts nearby. When the experiment and training had finished, it was discovered that adolescents in the target group had more confident in using English for communication. Moreover, they began to develop a sense of love of their hometowns because they had visited places and experienced agricultural and traditional way of life. They have learned their own origin; thus, they were proud of and impressed by their ancestors' wisdom.

\section{Scope of Research}

\subsection{Population and Sample}

Population in this research is the children and youth network in Sung Noen. Totally there are 578 people, 40 of whom are target group and selected by purposive sampling (Boonchom, 2002).

\subsection{Research Instruments}

Research instruments are classified in 3 categories: 1. curriculum 2. questionnaire 3. interview. All of them are clarified in detail below.

3.2.1 "Curriculum of English for Conservative Tourism for Junior Guides in Sung Noen District, Nakhon Ratchasima Province" has been developed from secondary data, field work, and the real need of local people in Sung Noen. The researcher categorized the collected data into 2 groups as follows.

1 Group 1 is the data collected from participatory process of government sector and people in Sung Noen District, Nakhon Ratchasima Province. Both sectors have brainstormed ideas of developing curriculum that match local people's need. In the curriculum, 8 conservative attractions were specified as follows.

1). Baan Non Bung Community

2). Routes of Muang Sema civilization and Pra non Temple

3). Sam Sib Sang Mountain

4). Wang Nane and Wang Cowboy waterfalls

5). Na Yom Fighting Cock Village

6). Sung Noen train station, part of the royal route that King Rama IX used to take

7). Ancient temples and Chinese culture

8). Sufficiency economy farms of village heads

2 Group 2 is the data collected from brainstorming session participated by English curriculum (B.Ed.) professors to develop the curriculum. In addition, tour guide training workshop is included in the curriculum so that the guides can do field work along the designed tour routes.

3.2.2 Questionnaires are designed to evaluate the quality and reflection of the curriculum. The target groups of these questionnaires are 1. youth 2. chief officers of Sung Noen Administrative Organization 3. foreign tourists.

Questionnaires are divided into 4 parts as follows.

1). General information of respondents

2). Achievement gained from using the curriculum

3). Satisfaction of the curriculum user

4). Suggestion for further development of the curriculum

3.2.3 Interview, which is in-depth survey, is created for different target groups: 1. Youth 2. chief officers of Sung Noen Administrative Organization 3. foreign tourists.

\subsection{Research period}

Ten months 


\subsection{Research Methodology}

To determine sample size, Non Probability Sampling formula was used to calculate. Furthermore, to define population, the researcher used sampling at a 95 percent confidence and significance level of 0.05 , and determine the size by using Cochran's formula (Boonprasert, 2003). The researcher conducted the research in 10 steps as follows.

Table 1. Ten steps of research methodology

\begin{tabular}{|c|c|}
\hline Step & Detail \\
\hline Step 1 & $\begin{array}{l}\text { The researcher explained research objectives to related sections: } 1 \text {. Youth } 2 \text {. chiefs of } \\
\text { Administrative Organizations } 3 \text {. involving people }\end{array}$ \\
\hline Step 2 & $\begin{array}{l}\text { The researcher and team studied data of basic English background knowledge of youth in Sung } \\
\text { Noen District, Nakhon Ratchasiama Province to prepare information suitable for potential to } \\
\text { learn English for communication In addition, the researcher directly asked the youth's need to } \\
\text { know how to prepare the content that matched their interest. The team collected data from } \\
\text { teachers at Foreign Language Department of Education Development Center in Sung Noen } \\
\text { District. }\end{array}$ \\
\hline Step 3 & $\begin{array}{l}\text { The researcher selected the focus group for improving English used to enhance tourism } \\
\text { potential. This group consisted of 1.the youth } 2 \text {.school directors } 3 \text {. English teachers } 4 \text { chiefs of } \\
\text { Administrative Organizations 5.stakeholders }\end{array}$ \\
\hline Step 4 & $\begin{array}{l}\text { The researcher and team collected in-depth data by asking local intellectuals or chiefs of } \\
\text { Administrative Organizations in order to acquire accurate and precise information about } \\
\text { conservative tourism without any errors. Then the acquired data was included in the content } \\
\text { used for English training for the youth in Sung Noen District. This data was separated into } \\
\text { primary and secondary data. }\end{array}$ \\
\hline Step 5 & $\begin{array}{l}\text { The researcher held a meeting for the team to prepare for the research and accomplish the } \\
\text { objectives. Besides preparation, the meeting was held to review and find some advice about the } \\
\text { process of creating English using activities to give the junior guides the greatest advantage. The } \\
\text { team had to prepare the information related to English for conservative tourism in Sung Noen } \\
\text { District, review its accuracy as well as completeness, and ensure that it match the real context. } \\
\text { The English structure need to be checked if it matched the content and is applicable, also. }\end{array}$ \\
\hline Step 6 & $\begin{array}{l}\text { The researcher and lecturers used the curriculum, and the scope of content was indicated as } \\
\text { follows. } 1 \text {. English for tourism in general } 2 \text {. English for conservative tourism } 3 \text {. English for } \\
\text { hotel business } 4 \text {. English for reception and public relations } 5 \text {. English for cultural attraction } \\
\text { recommendation } 6 \text {.English for restaurant workers. }\end{array}$ \\
\hline Step 7 & $\begin{array}{l}\text { Led the youth to do the field work as a guide taking foreign tourists to places in Sung Noen } \\
\text { District. }\end{array}$ \\
\hline Step 8 & Distribute questionnaires and interview forms. \\
\hline Step 9 & Process the research data and used it for analyzing and synthesizing performance. \\
\hline Step 10 & Conclusion \\
\hline
\end{tabular}

\subsection{Data Collection and Analysis}

The researcher collected and analyzed data in 3 phases based on Daniel's approaches (Daniel, 2011) which are 1. before research 2. during research 3. in the end of research. The researcher analyzed further by using "analysis and informal observation from video recording" and "informal interview" to describe and synthesize findings in accordance with the pattern of action research.

\section{Research Results}

The researcher separated the results in to 3 tables as follows. 
Table 2. The table of youth's satisfaction with curriculum of English for conservative tourism used for junior guides in Sung Noen District, Nakhon Ratchasima Province

\begin{tabular}{|c|c|c|c|c|}
\hline \multirow[t]{2}{*}{ No. } & \multirow[t]{2}{*}{ Detail } & \multicolumn{3}{|c|}{ Level of satisfaction } \\
\hline & & Excellent & Moderate & Poor \\
\hline 1 & $\begin{array}{l}\text { I have practiced all English skills for welcoming foreign tourists } \\
\text { visiting conservative attractions in Sung Noen. }\end{array}$ & $60 \%$ & $38 \%$ & $2 \%$ \\
\hline 2 & $\begin{array}{l}\text { I have done field work to practice skills as a tour guide by using } \\
\text { appropriate procedures that suits tourism context of Sung Noen. }\end{array}$ & $62 \%$ & $36 \%$ & $2 \%$ \\
\hline 3 & $\begin{array}{l}\text { I can integrate the acquired knowledge of English into learning in } \\
\text { common classrooms. }\end{array}$ & $60 \%$ & $38 \%$ & $2 \%$ \\
\hline 4 & $\begin{array}{l}\text { Procedures of the curriculum can encourage me to use English for } \\
\text { communication in situations related to conservative tourism. }\end{array}$ & $56 \%$ & $36 \%$ & $8 \%$ \\
\hline 5 & $\begin{array}{l}\text { The length of curriculum and procedure management is } \\
\text { appropriate. }\end{array}$ & $48 \%$ & $46 \%$ & $6 \%$ \\
\hline 6 & $\begin{array}{l}\text { I can apply skills and knowledge acquired from participating in } \\
\text { curriculum and procedures to the job, which is a tour guide, in the } \\
\text { future. It can be a job that can provide me and my family an } \\
\text { income. }\end{array}$ & $58 \%$ & $34 \%$ & $8 \%$ \\
\hline 7 & $\begin{array}{l}\text { The content in the curriculum and research procedures truly } \\
\text { matches the need of people in Sung Noen. }\end{array}$ & $69 \%$ & $30 \%$ & $2 \%$ \\
\hline 8 & $\begin{array}{l}\text { Content and procedures can evoke the sense of love of my } \\
\text { hometown and follows the curriculum. }\end{array}$ & $62 \%$ & $36 \%$ & $2 \%$ \\
\hline 9 & $\begin{array}{l}\text { I want this curriculum to be organized continuously for the } \\
\text { sustainable development of English use in order to enhance junior } \\
\text { guides' potential. }\end{array}$ & $70 \%$ & $25 \%$ & $5 \%$ \\
\hline 10 & $\begin{array}{l}\text { My satisfaction with overall organization of curriculum and } \\
\text { research procedures. }\end{array}$ & $66 \%$ & $26 \%$ & $8 \%$ \\
\hline
\end{tabular}

Table 3. The table of foreigh tourists' satisfaction with English skills and performance of junior guides in Sung Noen District, Nakhon Ratchasima Province

\begin{tabular}{lllll}
\hline No. & Detail & \multicolumn{2}{l}{ Level of satisfaction } \\
& & Excellent & Moderate & Poor \\
\cline { 2 - 4 } 1 & Junior guides can communicate in English. & $62 \%$ & $20 \%$ & $18 \%$ \\
2 & Junior guides can recommend conservative attractions in English. & $71 \%$ & $15 \%$ & $14 \%$ \\
3 & $\begin{array}{l}\text { Junior guides can recommend related places such as } \\
\text { accommodation, restaurants and drug stores efficiently. }\end{array}$ & $65 \%$ & $25 \%$ & $10 \%$ \\
4 & Junior guides are confident when they communicate in English. & $63 \%$ & $28 \%$ & $9 \%$ \\
5 & $\begin{array}{l}\text { Junior guides can provide information related to tourism correctly } \\
\text { and appropriately. }\end{array}$ & $48 \%$ & $30 \%$ & $22 \%$ \\
6 & $\begin{array}{l}\text { Junior guides behave in a good manner when they are on their } \\
\text { duty. }\end{array}$ & $58 \%$ & $20 \%$ & $22 \%$ \\
7 & $\begin{array}{l}\text { Junior guides dress properly when they are on their duty. } \\
8\end{array}$ & $58 \%$ & $20 \%$ & $22 \%$ \\
\hline
\end{tabular}


Table 4. The table of chief administrators' and stakeholders' satisfaction with developing and using English curriculum of conservative tourism for junior guides in Sung Noen District, Nakhon Ratchasima Province

\begin{tabular}{|c|c|c|c|c|}
\hline \multirow[t]{2}{*}{ No } & \multirow[t]{2}{*}{ Detail } & \multicolumn{3}{|c|}{ Level of satisfaction } \\
\hline & & Excellent & Moderate & Poor \\
\hline 1 & $\begin{array}{l}\text { Research procedures were managed follow research methodology } \\
\text { to develop the curriculum most efficiently. }\end{array}$ & $66 \%$ & $32 \%$ & $2 \%$ \\
\hline 2 & $\begin{array}{l}\text { Nakhon Ratchasima Rajabhat Unniversity English curriculum } \\
\text { (B.Ed.) teachers' and the researcher's readiness as well as } \\
\text { efficiency of developing the curriculum. }\end{array}$ & $67 \%$ & $15 \%$ & $18 \%$ \\
\hline 3 & $\begin{array}{l}\text { The curriculum was organized in accordance with English } \\
\text { teaching and learning policy in sung Noen District. }\end{array}$ & $74 \%$ & $20 \%$ & $6 \%$ \\
\hline 4 & $\begin{array}{l}\text { The developed curriculum truly matches the context of youth's } \\
\text { and stakeholders' need in Sung Noen District. }\end{array}$ & $80 \%$ & $10 \%$ & $10 \%$ \\
\hline 5 & $\begin{array}{l}\text { The content of the developed curriculum matches the context of } \\
\text { conservative and cultural tourism in Sung Noen. }\end{array}$ & $79 \%$ & $11 \%$ & $10 \%$ \\
\hline 6 & $\begin{array}{l}\text { The created curriculum can be used for welcoming and giving } \\
\text { information to foreign tourists efficiently. }\end{array}$ & $69 \%$ & $14 \%$ & $17 \%$ \\
\hline 7 & $\begin{array}{l}\text { This curriculum can be a model of English teaching curriculum } \\
\text { developed by the collaboration between universities and local } \\
\text { administrative organizations, and it can be applied to other areas } \\
\text { in Thailand. }\end{array}$ & $85 \%$ & $10 \%$ & $5 \%$ \\
\hline 8 & My satisfaction with overall curriculum. & $88 \%$ & $10 \%$ & $2 \%$ \\
\hline
\end{tabular}

\section{Discussion}

The researcher discussed the result based on the analysis and synthesis of research instruments listed in 3 groups as follows.

\subsection{Youth}

The survey participants at 69 percent see that the curriculum and research procedures truly match the Sung Noen people's need. Moreover, 70 percent of them want the curriculum to be organized continuously for sustainable development of English, which is used for junior guides' potential enhancement.

\subsection{Foreign Tourists}

The survey participants at 69 percent see that junior guides can give information about tourist attractions in English efficiently, and 71 percent of them think that junior guides can give information about conservative attractions in English.

\subsection{Chief Administrators and Stakeholders in Sung Noen District}

The survey participants at 80 percent see that the created curriculum truly matches the context of Sung Noen youth's and stakeholders' need. In addition, 85 percent of them think that this curriculum can be a model of English teaching curriculum developed by the collaboration between universities and local administrative organizations, and it can be applied to other areas in Thailand.

\section{Conclusion}

The important point of this research is to begin the research and define the research problem. After conducting the survey on site on the true need of the youth, chief administrators and people from all sectors, the researcher and team designed the curriculum. It is "Curriculum of English for Conservative Tourism for Junior Guides in Sung Noen District, Nakhon Ratchasima Province". The experiment took 10 months, and the result is successfully satisfying. This research was conducted based on objectives as follows.

1). Achievement in English teaching model for local development, resulting from English curriculum (B. Ed.) students' participation on out-of-classroom learning management. This model focuses on improving English skills of students along with developing the sense of love of their hometowns. 
2). Achievement in curriculum of English for conservative tourism for junior guides in Sung Noen District, Nakhon Ratchasima Province.

3). Achievement in the promotion of conservative tourism in Sung Noen District, Nakhon Ratchasima Province to make it well-known among foreign tourists.

4). Achievement in local development and collaboration between the university and local administrative organizations. In the future, this model can be used to improve quality of life of people in other areas in Thailand.

\section{Suggestion}

After the research was complete, it was found that the research spread benefits widely, that is, the prototype of collaboration between a university, which was Nakhon Ratchasiama Rajabhat University, and a local organization, which was Sung Noen Subdistrict Organization. In addition, an interesting result from the research was more income gained from tourism in Sung Noen District, Nakhon Ratchasima Province between April 2016 and June in the same year. Total income index from tourism was higher when compared to the same time of the previous year. Forty two percent of the income came from youth doing a part-time job, a tour guide. There were good effects on the growth of hotel booking, sales of shops and restaurants as well as profit of other related attractions. That was considered as a way that generated household income in accordance with economic chain construction approaches. The result was also matched with the analysis of tourist questionnaire and interview. The junior guides' ability to communicate and provide information about tourism in English was evaluated, and 69 percent of them considered it good. This result also accorded with the evaluation done by the youth and stakeholders on the curriculum of English for conservative tourism for junior guides, and 75 percent considered it very good, matching with the synthesis from the interview. All of these can indicate that the quality of this curriculum is very good. That is because the curriculum was created to be applicable to the local tourism context and match the true need of users that are youth and all related sectors in Sung Noen District, Nakhon Ratchasima Province.

The interesting point is that the researcher guided English curriculum (B.Ed.) students in training on out-of-classroom learning activities. The researcher focused on the development of students' English skills as well as the sense of love of their hometowns. The development is based on connectivism and subjects that students have attended, and it aims to provide academic services and develop local communities. The subjects integrated into connectivism are 1. Research for English Language Learning Development (207483) 2. Teaching and Learning in English (207477) 3. English Learning and Teaching Innovation (207479) 4. Out-of-classroom English Learning Management (207467). These research methods comply with the mission of Rajabhat University nationwide in terms of policy. The policy is "creation of teachers or academic personnel, who are able to develop local communities, along with public consciousness construction." Twenty English curriculum (B. Ed.) students, who were in the fourth year and attended the class of Research for English Language Learning Development 207483), participated in this research. As a result, they have direct experience in conducting research for English learning improvement, designing curriculum for English teaching, creating activities for Sung Noen youth leaders' English potential improvement, Collecting data on site including analyzing research data, and developing good relationship between students and local people.

The youth, who are the target group of this research, have learned how to use communicative English for conservative tourism. Besides better English skills, they have confidence to communicate and welcome foreign tourists in English follow the process of the research plan made by the team. Therefore, the youth have a chance to recommend conservative attractions at the actual places along with learn traditional way of life and culture in their own local communities. This aspect has developed the youth's sense of love in their hometowns and helped them to understand how English potential improvement can be developed further and create a job in the future

\section{References}

Anzar, U. (2001). An exploratory study of factor which have contributed to the Sustainabillity of community participation in education in balochistan.

Boonchom, S. (2002). Fundamental Research (7th ed.). Bangkok: Suveeriyasarn.

Boonprasert, M., et al. (2003). Research and Higher Education Administrative System Development, A Contemporary of Higher Education Administrative Management. Bangkok: MPT.

Daniel, S. D. (2003). Examination of the Relationship Between School Board Governace, Community, and Superintendent Types. Dissertion Abstracts International, 1, 111-113. 
Jeremy, H. (2009). The Practice of English Language Teaching. US : Pearson.

Koomkhainam, T. (2007). Educational Administration Techniques. Chaiyaphoom, Chayaphom Rajabhat University.

Kwantip, C. (2014). Strategies for Driving Basic Education towards ASEAN Community Retrieved December 9, 2014, from http://www.tcithaijo.org/index.php/Veridian-E-ournal/article/viewFile/17875/23391

Larbnongsang, S. (2012). Social Development for Thai people in the ASEAN community. Journal of Education and Social Development, 8(1), 6-18.

Parker, C. (2011). Teaching English Around the World. US: Pearson.

Ratanakorn, A. et al. (2003). Indicators, Products, and Outcomes Rajabhat University. Bangkok, Jankasem Rajabhat.

Thira, R. (2011). As a professional in the preparation and administration of Education reform.

Wendy, A. (2013). Teaching English to Children. UK: Longman.

Wimontham, O. (2016). The Integrating Sciencetor Quality of Life of People Age Group in Sung Noen District, Nakhon Ratchasima Province. Nakhon Ratchasima: National Research Council of Thailand.

Wimontham, O. (2016). The strengthener to Kids and Juvenile for decreasing the problem of game online addiction in Sung Noen, Nakhon Ratchasima Province. Nakhon Ratchasima: National Research Council of Thailand.

Yule, G. (2010). The Study of Language. US : Pearson. https://doi.org/10.1017/CBO9780511757754

\section{Copyrights}

Copyright for this article is retained by the author(s), with first publication rights granted to the journal.

This is an open-access article distributed under the terms and conditions of the Creative Commons Attribution license (http://creativecommons.org/licenses/by/4.0/). 